\title{
Racial differences in incidence of juvenile-onset Type 1 diabetes: epidemiologic studies in southern California
}

\author{
M. Lorenzi, E. Cagliero and N.J.Schmidt \\ Department of Medicine, Division of Endocrinology and Metabolism, University of California at San Diego, San Diego, and Virus and \\ Rickettsial Disease Laboratory, California Department of Health Services, Berkeley, CA, USA
}

\begin{abstract}
Summary. We have studied the epidemiologic characteristics of insulin-dependent (Type 1) diabetic patients aged 0-19 in a city (San Diego, southern California, USA) characterized by an impressive racial diversity and especially mild and constant climatic conditions. Ascertainment was through retrospective review of medical records in 19 hospitals. For the 3 years 1978-1981 the mean annual incidence of diabetes was 7.3 cases $/ 100,000$, with no statistical difference between the sexes. The observed incidence rates in the various ethnic groups was significantly different from expected $(p<0.03)$, with an excess of cases among Caucasians and fewer than expected cases among Mexicans, Blacks and Orientals. There was no identifiable seasonal trend. Some of the clinical char-
\end{abstract}

acteristics at diagnosis differed between the sexes: males were slightly older ( $9.3 \pm 5.2$ years versus $8.8 \pm 3.9$ for females), had a shorter duration of diabetes-related symptoms and a higher frequency of infections both at the time of diabetes diagnosis and in preceding months. Females tended to have a higher frequency of Type 1 diabetes in first-degree relatives. This study documents for the first time that, among multiple racial groups living in the same environment, Caucasians are at the highest risk of developing juvenile-onset Type 1 diabetes.

Key words: Type 1 diabetes, juvenile diabetes, incidence, racial differences, seasonality.
The pathogenesis of Type 1 (insulin-dependent) diabetes involves both genetic and environmental factors [1]. Among genetic factors, the HLA specificities DR3 or DR4 have been found associated with Type 1 diabetes in all ethnic groups thus far examined: European and North American Caucasians [2], African and American Blacks [2], Japanese [2, 3], Chinese [4], and MexicanAmericans [5]. On the other hand, the frequencies of DR3 and DR4 are not uniform across the above ethnic groups [6]. When compared to Caucasians, Mexicans have a slightly lower frequency of DR3, Blacks of DR4 and Japanese rarely have DR3. One may ask to which extent these or other genetic population characteristics impinge on incidence rates of Type 1 diabetes within the individual ethnic group under consideration. This question could be addressed optimally in a circumscribed geographical area so as to equalize the contribution of environmental factors. Previous studies which have suggested a lesser frequency of Type 1 diabetes in nonWhites include prevalence studies [7, 8] and one incidence study comparing solely Blacks versus Whites [9]. In view of its impressive racial diversity, the city of San Diego in southern California, USA, appeared well suited for expanding observations to other ethnic groups.
In addition, this city has the smallest seasonal variation in temperature of any major city in North America and thus offered the opportunity to evaluate seasonality of incidence of diabetes independent of stressful climatic changes.

\section{Subjects and methods}

Our investigation addressed Type 1 diabetic patients diagnosed up to age 19. The studies were approved by the Committee on Investigations on Human Subjects of the University of California San Diego and by the appropriate committee of the other hospitals. The investigation was retrospective, and ascertainment of the cases was accomplished by retrospective review of hospital records. The reliability of this method is based on two assumptions that have gone thus far unchallenged: that newly discovered juvenile-onset insulin-dependent diabetic patients are referred to a hospital, and that the referrals are made to hospitals with $x$ pediatric or a medical ward. Because San Diego is the largest city in a 100-mile radius, we also assumed that essentially no San Diego residents would be admitted to hospitals elsewhere. On the other hand, admissions to San Diego hospitals of juveniles residing elsewhere were anticipated, and specifically identified through our survey methodology. We chose to investigate the years 1978-81 in order to base computations on current census data (1980 Census).

We contacted all nineteen hospitals in San Diego which have pediatric or medical wards and obtained authorization by the appropri- 
Table 1. Annual incidence and sex distribution of Type 1 diabetic patients (aged 0-19) in San Diego, California, USA

\begin{tabular}{llrrl}
\hline & \multicolumn{2}{l}{ Number of cases } & \multicolumn{2}{l}{$\begin{array}{l}\text { Rate per } \\
100,000\end{array}$} \\
\cline { 2 - 4 } & Total & Males & Females & \\
\hline $1978-79$ & 27 & 11 & 16 & 9.7 \\
$1979-80$ & 17 & 15 & 2 & 6.1 \\
$1980-81$ & 17 & 8 & 9 & 6.1 \\
Total & 61 & 34 & 27 & Mean 7.3 \\
\hline
\end{tabular}

Table 2. Incidence by race of Type 1 diabetic patients (aged 0-19) over a 3-year period in San Diego, California, USA

\begin{tabular}{lllll}
\hline & Caucasian & Mexican & Black & Oriental \\
\hline $\begin{array}{l}\text { Number of individuals } \\
\text { aged 0 - 19a }\end{array}$ & 167,646 & 56,934 & 30,033 & 20,337 \\
$\begin{array}{l}\text { Number of expected DM } \\
\text { cases }\end{array}$ & 36.8 & 12.5 & 6.6 & 4.4 \\
$\begin{array}{l}\text { Number of observed DM } \\
\text { cases }\end{array}$ & 48 & 7 & 3 & 3 \\
$\qquad \begin{array}{r}\mathrm{X}^{2}=8.26 \\
p<0.03\end{array}$ & & & \\
\hline
\end{tabular}

"Calculated from Tables 14, 15, 16, 25 and 30 of the California Section of the 1980 Census of Population and Housing, US Department of Commerce. ${ }^{b}$ Calculated on the basis of the observed overall incidence rate ( 7.3 cases $/ 100,000$ per year) to indicate the number of cases expected in the individual racial group if the incidence rate had been the same across all groups

Table 3. Clinical characteristics of 95 Type 1 diabetic patients aged 0-19 diagnosed over 3-year period in San Diego, California, USA

\begin{tabular}{llll}
\hline & $\begin{array}{l}\text { Males } \\
(n=54)\end{array}$ & $\begin{array}{l}\text { Females } \\
(n=41)\end{array}$ & $\begin{array}{l}\text { Total } \\
(n=95)\end{array}$ \\
\hline $\begin{array}{l}\text { Age } \\
\text { (years, M SD) }\end{array}$ & $9.3 \pm 5.2$ & $8.8 \pm 3.9$ & $9.0 \pm 4.5$ \\
$\begin{array}{l}\text { Duration of symptoms } \\
\text { (weeks, M SD) }\end{array}$ & $2.5 \pm 2.4$ & $4.2 \pm 3.5$ & $3.3 \pm 2.8$ \\
$\begin{array}{l}\text { Associated infections at } \\
\text { diagnosis of diabetes (\%) }\end{array}$ & 27.8 & 17.1 & 23.1 \\
$\begin{array}{l}\text { Reported illnesses 1-3 months prior } \\
\text { to diagnosis of diabetes (\%) }\end{array}$ & 37.0 & 21.9 & 30.5 \\
$\begin{array}{l}\text { Family history of Type 1 diabetes } \\
\text { (\%) (parents or siblings) }\end{array}$ & 12.5 & 21.0 & $16.2^{\mathrm{a}}$ \\
$\begin{array}{l}\text { Family history of Type 2 diabetes } \\
\text { (\%) (grandparents or parents) }\end{array}$ & 31.0 & 28.9 & $30.0^{\mathrm{a}}$ \\
$\begin{array}{l}\text { Personal history of atopy (\%) } \\
\text { Family history of atopy (\%) }\end{array}$ & 14.8 & 12.2 & 13.7 \\
\hline
\end{tabular}

a The frequencies of positive family history refer to the 90 cases ( 51 males and 39 females) in which the proband was not adopted

ate hospital authority to review all records relative to hospital admissions of juveniles aged $0-19$ with a diagnosis of diabetes mellitus over the period July 1978-June 1981 ( 3 years). We requested access to all records in order to ensure completeness of ascertainment insofar as only few hospitals could either code or identify new diagnosis. All charts were reviewed by the same two investigators, who obtained the following information on a standardized form: patient's initials and

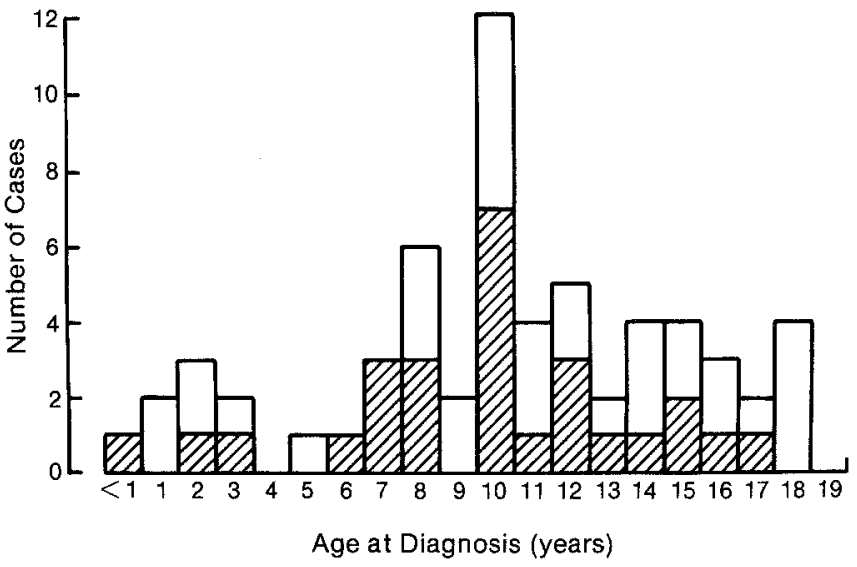

Fig. 1. Age at diagnosis of Type 1 diabetes by sex $(\square$ males, $n=34$; 叉females, $n=27$ )

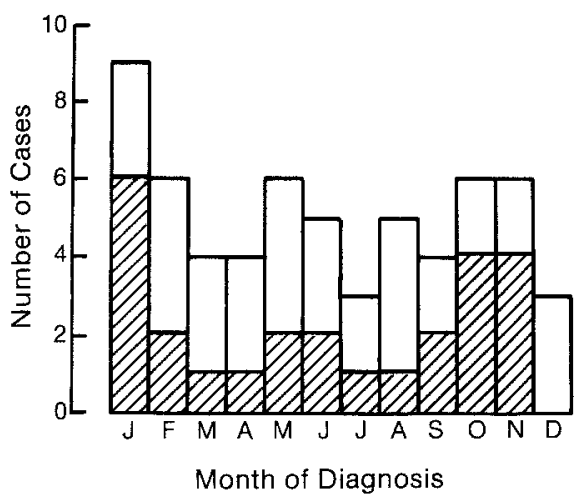

Fig. 2. Month of diagnosis of Type 1 diabetes by sex $\square$ males, $n=34$; females, $n=27$ )

hospital number, sex, race, birthdate, place of residence; date of diagnosis of diabetes; laboratory values on admission (plasma glucose, ketones, $\mathrm{pH}$ or bicarbonate, urine glucose and ketones); stated duration of polyuria, polydipsia, weight loss; reported recent illnesses (1-3 weeks prior to admission) and more remote illnesses (in the preceding 1-3 months); overall medical history with particular attention to mention of atopy; family history recording adoption, number and age of siblings, occurrence of diabetes (Type 1 versus Type 2) and atopy in siblings, parents and grandparents. All patients fit one definition of Type 1 diabetes: ketonuria on admission and insulin therapy on discharge.

Analysis of incidence was restricted to patients whose residence was in the city of San Diego and was computed on the basis of the city's demographic data provided in the 1980 census. Race was obtained from the chart and classified under the following categories: Caucasian, Black, Mexican, Oriental. Respective denominators for the above ethnic categories were: White not of Spanish origin, Black not of Spanish origin, individuals of Spanish origin, Orientals; all aged $0-19$ years (Tables $14,15,16,25$ and 30 of the California section of the 1980 Census of Population and Housing, US Department of Commerce). Seasonal variation in incidence was analyzed by grouping the frequencies into four seasons: December-February, March-May, June-August, September-November.

Statistical analysis of incidence and seasonality data was performed with the Chi-square test statistic of the observed and expected values. For the analysis of seasonality the expected frequencies of new diagnoses were assumed to be uniform across seasons. 


\section{Results}

All 19 hospitals we contacted in the city of San Diego agreed to participate in the study. In each of the 3 years under investigation, $97 \%$ of the cases were consistently detected at 6 major hospitals (Children's, Kaiser, Naval Regional Medical Center, UCSD Medical Center, Mercy, Scripps Memorial). On the basis of retrospective chart review, a total of 95 juveniles (54 males and $41 \mathrm{fe}-$ males) were diagnosed with insulin-dependent diabetes between July 1978 and June 1981. Thirty-four resided in neighboring towns; of these, 6 were Mexican and all other Caucasian.

The analysis of incidence and racial distribution, in order to be based on specific demographic data, takes into account only the 61 patients who resided in the city of San Diego at the time of diagnosis. Annual incidence (Table 1) was slightly higher in 1978-79 $(9.7 / 100,000)$ as compared to the two following years $(6.1 / 100,000)$. The mean incidence rate over the three years was $7.3 / 100,000$. There was no statistical difference in incidence between the sexes $\left(\mathrm{X}^{2}=0.68, \mathrm{NS}\right)$. The observed incidence rate in the various ethnic groups (Table 2) was significantly different from expected $\left(\mathrm{X}^{2}=8.26, p<\right.$ 0.03 ), with an excess of cases among Caucasians and fewer than expected cases among Mexicans, Blacks and Orientals. The distribution of age at diagnosis (Fig.1) failed to show major differences between males and females. Compared to demographic data, the incidence varied greatly in the different age groups: over the 3 years of observation there were 6.2 cases $/ 10^{5}$ aged $<$ 5 years, 10.4 cases $/ 10^{5}$ aged $5-9$ years, 20.6 cases $/ 10^{5}$ aged $10-14$ years, and 7.3 cases $/ 10^{5}$ aged $15-19$ years. There was clearly a disproportionate excess of cases in the 10-14 years age group and fewer than expected cases in the $<5$ years and 15-19 years age groups $\left(\mathrm{X}^{2}=16.62, p<0.001\right)$.

When the seasonal trend for new diagnoses over the 3 -year period was analyzed cumulatively or by sex (Fig. 2) no seasonality could be identified $\left(\mathrm{X}^{2}=0.99\right.$, NS). It was of interest that over the three years covered by the investigation, there had been one "alert" for excess absenteeism (>50\%) in the San Diego school system. This was due to a "viral gastroenteritis" that sequentially affected high, junior high, and elementary school students in the period between Thanksgiving and Christmas 1980. We could not detect an excess of Type 1 diabetes diagnoses in the 6 months (January-June 1981) following the epidemic.

The other clinical characteristics ascertained in the patient population are summarized for all the 95 cases detected (Table 3 ). The frequency of positive family histories refers to the 90 cases in which the proband was not adopted. Among male cases, there was a tendency for a shorter duration of diabetes-related symptoms and more infections both at the time of diagnosis of diabetes and in preceding months; at both times the leading diagnoses were sore throat, otitis media and upper respi- ratory infection. A positive family history for insulindependent diabetes was recorded in $16.2 \%$ of the cases $(12.5 \%$ of males and $21 \%$ of females); this form of diabetes had occurred either in one of the parents or in one of the siblings. The prevalence of Type 2 diabetes was similar in families of males and females $(31 \%$ versus $28.9 \%$ respectively). Personal history of atopy was also similar between males and females $(14.8 \%$ in males versus $12.2 \%$ in females); 8 of the children with allergies $(9.1 \%)$ had a negative family history of atopy. The leading atopic pathologies were allergic rhinitis and asthma.

\section{Discussion}

This study on the epidemiology of juvenile-onset Type 1 diabetes is not a large one, but it contributes some novel insights through its unique features. At variance with other studies [10-12], it was conducted in a population harboring an impressive racial diversity and in a geographical area enjoying especially mild and constant climatic conditions. In this setting the incidence of Type 1 diabetes in juveniles aged $0-19$ was significantly higher among Caucasians than among Blacks, Mexican and Orientals; the seasonal pattern of onset mostly observed in northern countries $[10,12]$ was not readily apparent.

Previous studies of racial and ethnic differences in the frequency of juvenile-onset Type 1 diabetes were either prevalence studies or studies which addressed a limited number of groups. Thus, a higher prevalence has been observed among Michigan White children versus non-Whites [7], and among Israel children born in Europe-America versus children born in Asia-Africa [8]; a higher incidence has been reported in Caucasians versus Blacks in Allegheny Country [9]. Our findings are consistent with these data and for the first time clearly document that, among multiple racial groups, Caucasian children are at the highest risk of developing Type 1 diabetes. This is compatible with the observation that the highest incidence rates for juvenile diabetes have been reported from northern European countries, which are characterized by ethnically stable and nonmigrating Caucasian populations. In those countries the yearly incidence rates per 100,000 are as high as 13.2 in Denmark [13], 19.6 in Sweden [14]. 18.8 in Norway [15], 18.0 in Scotland [16] and over 30.0 in Finland [17].

Racial differences that are detected within the same environment might stem not only from genetic characteristics but also from socioeconomic factors. The latter are unlikely, however, to play a systematic role: one study found a lower incidence of Type 1 diabetes in low-income groups [11], another one the opposite [13], and a third failed to identify any relationship between incidence of juvenile diabetes and social class [18]. Among genetic factors a consistent association with Type 1 diabetes has been found for the HLA specificities DR3 and DR4, and such association extends to all ethnic groups thus far examined [2-5]. The frequencies 
of the DR3 and DR4 haplotypes vary, however, among racial and ethnic groups and tend to be higher among European and North American Caucasians [6]. In nonCaucasian populations the lower frequency of individuals carrying such specificities may result in a lesser incidence of Type 1 diabetes, especially when considering that the highest risk for Type 1 diabetes appears to be conferred by HLA DR3/4 heterozygosity $[2,19]$. On the other hand, that other genetic factors might contribute to the racial differences in incidence of Type 1 diabetes is certainly a possibility.

The overall incidence of juvenile-onset Type 1 diabetes in San Diego is lower than the incidence recorded in various other western populations [10-17]; this is probably a consequence of the racial diversity of the population under study. In fact, the mean incidence rate for Caucasians in our survey was 10 cases $/ 10^{5}$ per year, comparing favorably with other studies in Caucasian populations.

Seasonality of incidence of juvenile diabetes, manifested by a major peak in winter and a minor one in autumn, has been observed in several [12-16] but not all [20] geographic locations. It is of interest that a survey [20] which failed to detect a seasonal pattern despite a very large study population was conducted in an area (New Zealand) enjoying a milder climate than most other locations studied. Since the seasonality of incidence of Type 1 diabetes has been attributed to the seasonality of infectious illnesses $[10,12]$ one may speculate that the less stressful living conditions in milder climates may lessen the clustering and/or the severity of seasonal infections and consequently of their immediate impact on the onset of clinical diabetes.

Some of the clinical characteristics recorded in our patient population offer further insight into the epidemiology of juvenile-onset Type 1 diabetes and prompt some speculations about its pathogenesis. The shorter duration of "diabetic" symptoms and the higher frequency of infections at the time of diabetes diagnosis observed in male patients may be at the basis of the more pronounced seasonal pattern of onset recorded for male cases in some studies [21, 22]. The greater frequency of infectious illnesses in male patients - which may reflect a higher susceptibility of males to infectious diseases [23] - and instead the greater frequency of positive family history for insulin-dependent diabetes in female patients suggest the hypothesis that more male cases may develop on the basis of an acute infectious insult (subclass $c$ of [1]) while more female cases may develop on the basis of a propensity to autoimmunity (subclass a of [1]). The diverse etiopathogenesis could then account for the overall similar incidence of insulindependent diabetes in the two sexes, at variance with the female preponderance characteristic of most other autoimmune diseases. The data on which such proposition is based are retrospective, and thus subject to being incomplete. Since, however, the frequency of Type 1 diabetes in first degree relatives recorded in our popula- tion is equal or greater than that reported in previous studies [24], it is unlikely that gross underestimation should have occurred, and then solely or preferentially for the male cases. Prospective studies will be necessary to systematically address this hypothesis.

We collected data on allergic manifestations in the newly diagnosed Type 1 diabetic patients because a previous study had report a significantly lower frequency of atopy in diabetic children [25]. In our patients the frequency of atopy was similar [25] or above [26] that reported for non-diabetic children, in particular when considering the frequency in children without a family history of atopy [26]. In the absence, however, of data from a local control group, no confident suggestion can be drawn of an increased tendency to allergic diseases in juveniles who develop Type 1 diabetes.

Acknowledgements. We are indebted to the Administrations of the 19 San Diego hospitals for providing us with the opportunity to review medical records, and to Prof. E. Barrett-Connor for suggestions and critical review of the manuscript. This study was supported in part by a grant from the American Diabetes Association, Southern California Affiliate to M.L. and by Grant AI-15990 from The National Institute of Allergy and Infectious Diseases to N. J.S.

\section{References}

1. National Diabetes Data Group (1979) Classification and diagnosis of diabetes mellitus and other categories of glucose intolerance. Diabetes 28: 1039-1057

2. Svejgaard A, Platz P, Ryder LP (1980) Insulin-dependent diabetes mellitus. In: Terasaki PI (ed) Histocompatibility testing 1980 - Report of the 8th International Histocompatibility Workshop. UCLA Tissue Typing Laboratory, Los Angeles, pp 638-656

3. Sakurami T, Ueno Y, Nagaoka K, Kuno S, Iwaki Y, Park MS, Terasaki PI (1982) HLA-DR specifications in Japanese with juvenileonset insulin-dependent diabetes mellitus. Diabetes 31: 105-106

4. Lee BW, Chan SH, Tan SH, Wee GB, Yap HK, Wong HB, Tan CL, Tan KW (1984) HLA-system in Chinese children with insulindependent diabetes mellitus: A strong association with DR3. Metabolism 33: 1102-1105

5. Zeidler A, Loon J, Frasier SD, Kumar D, Penny R, Terasaki P (1980) HLA-DRw antigens in Mexican-American and BlackAmerican diabetic patients. Diabetes 29: 247-250

6. Baur MP, Danilovs JA (1980) Population analysis of HLA-A, B, $\mathrm{C}$, DR and other genetic markers. In: Terasaki PI (ed) Histocompatibility testing 1980 - Report of the 8th International Histocompatibility Workshop. UCLA Tissue Typing Laboratory, Los Angeles, pp 955-976

7. Gorwitz K, Howen GG, Thompson T (1976) Prevalence of diabetes in Michigan school-age children. Diabetes 25:122-127

8. Cohen T (1971) Juvenile diabetes in Israel. Israel J Med Sci 7 : $1558-1561$

9. LaPorte RE, Fishbein HA, Drash AL, Kuller LH, Schneider BB, Orchard TJ, Wagener DK (1981) The Pittsburgh insulin-dependent diabetes mellitus (IDDM) registry. Diabetes 30: 297-284

10. Gamble DR (1980) The epidemiology of insulin dependent diabetes, with particular reference to the relationship of virus infection to its etiology. Epidemiol Rev 2: 49-70

11. Colle E, Siemiatycki J, West R, Belmonte MM, Crepeau MP, Poirier R, Wilkins J (1981) Incidence of juvenile onset diabetes in Montreal - Demonstration of ethnic differences and socio-economic class differences. J Chron Dis 34: 611-616 
12. Fleegler FM, Rogers KD, Drash A, Rosenbloom AL, Travis LB, Court JM (1979) Age, sex, and season of onset of juvenile diabetes in different geographic areas. Pediatrics 63:374-379

13. Christau B, Kromann H, Andersen OO, Christy M, Buschard K, Arnung K, Kristensen IH, Peitersen B, Steinrud J, Nerup J (1977) Incidence, seasonal and geographical patterns of juvenile-onset insulin-dependent diabetes mellitus in Denmark. Diabetologia 13: 281-284

14. Sterky G, Holmgren G, Gustavson KH, Larsson Y, Lundmark KM, Nilsson KO, Samuelson G, Thalme B, Wall S (1978) The incidence of diabetes mellitus in Swedish children 1970-75. Acta Paediatr Scand 67: 139-143

15. Joner G, Sovik O (1981) Incidence, age at onset and seasonal variation of diabetes mellitus in Norwegian children 1973-77. Acta Paediatr Scand 70: 329-335

16. Patterson CC, Thorogood M, Smith PG, Heasman MA, Clarke JA, Mann JI (1983) Epidemiology of type 1 (insulin-dependent) diabetes in Scotland 1968-1976: Evidence of an increasing incidence. Diabetologia 24: 238-243

17. Koivisto VA, Akerblom KH, Wasz-Hockert O (1976) The epidemiology of juvenile diabetes mellitus in Northern Finland. Nordic Council for Arctic Medical Research; Report 15: 58-65

18. LaPorte RE, Orchard TJ, Kuller LH, Wagener DK, Drash AL, Schneider BB, Fishbein HA (1981) The Pittsburgh insulin dependent diabetes mellitus registry. Am J Epidemiol 114: 379-384

19. Platz P, Jakobsen BK, Morling N, Ryder LP, Svejgaard A, Thomsen M, Christy M, Kromann H, Benn J, Nerup J, Green A, Hauge M (1981) HLA-D and -DR antigens in genetic analysis of insulin dependent diabetes mellitus. Diabetologia 21: 108-115
20. Crossley JR, Upsdell M (1980) The incidence of juvenile diabetes mellitus in New Zealand. Diabetologia 18: 29-34

21. Gray RS, Duncan LJP, Clarke BF (1979) Seasonal onset of insulin dependent diabetes in relation to sex and age at onset. Diabetologia 17:29-32

22. Fishbein HA, LaPorte RE, Orchard TJ, Drash AL, Kuller LH, Wagener DK (1982) The Pittsburgh insulin-dependent diabetes mellitus registry: Seasonal incidence. Diabetologia 23: 83-85

23. Washburn TC, Medearis DN Jr, Childs B (1965) Sex differences in susceptibility to infections. Pediatrics 35: 57-64

24. Calnan M, Peckham CS (1977) Incidence of insulin-dependent diabetes in the first sixteen years of life. Lancet 1: 589

25. Hermansson B, Holmgren G, Samuelson G (1971) Juvenile diabetes mellitus and atopy. Human Hered 21: 504-508

26. Slavin RG, Smith LJ (1980) Epidemiologic considerations in atopic disease. $I n$ : Bierman CW, Pearlman DS (eds) Allergic diseases of infancy, childhood and adolescence. Saunders, Philadelphia London Toronto, pp 165-172

Received: 12 April 1985

and in revised form: 20 August 1985

Dr. M.Lorenzi

University of California San Diego Medical Center (H-811-C)

225 Dickinson Street

San Diego, CA 92103

USA 